\title{
A Rare Cause of Acute Abdomen: Torsion of the Gallbladder
}

\author{
Emir Eroler ${ }^{1}$, Uğur Duman' ${ }^{1}$ Deniz Necdet Tihan', Emrah Mehmet Bayam', Evren Dilektaşlı', Kazım Şenol' ${ }^{1}$ Özgür Dandin² \\ 'Clinic of General Surgery, Şevket Yılmaz Training and Research Hospital, Bursa, Turkey \\ 2Department of General Surgery, Bursa Military Hospital, Bursa, Turkey
}

\begin{abstract}
Gallbladder (GB) torsion is defined as a rotation of the GB on its mesentery along the axis of the cystic duct and cystic artery. It is a rare case that might be the cause of GB necrosis and consequent acute abdomen. To date, approximately 500 patients with GB torsion have been reported. In this case, the patient is a 42-year-old woman who was admitted to our hospital with abdominal pain. The patient was subjected to laparotomy; during the operation, a GB torsion resulting in necrosis was observed, and cholecystectomy was performed. (Eurasian J Emerg Med 2015; 14: 197-8)
\end{abstract}

Keywords: Acute abdomen, gallbladder, torsion, necrosis, emergency surgery, cholecystectomy

\section{Introduction}

Gallbladder (GB) torsion is a very rare clinical entity and was first described in 1896 by Wendel (1). It may be seen commonly in elderly individuals and in women with thin body type but affecting all age groups $(2,3)$. There are approximately 500 cases reported and the recent increase in reported cases may be because of increased mean lifetime of the population (4). Recent reports also suggest that incidence is higher than expected (5). The patients usually complain nonspecific symptoms such as abdominal pain, nausea, and vomiting. Physical signs may interfere with the signs of acute cholecystitis and acute appendicitis. GB may be palpable on the upper right quadrant. Surgical management is performed for GB torsion. Many patients have the exact diagnosis during surgical exploration. The surgical management involves performing cholecystectomy with detorsion of GB (6).

\section{Case Presentation}

A 42-year-old female patient had been admitted to the emergency service with complaints of acute abdominal pain, nausea, and vomiting. She had no specific medical history. On physical examination, tenderness on all quadrants of the abdomen (most evident on the upper and lower right quadrants) had been found. Murphy's sign was negative. On complete blood count testing, white blood cell count was $17400 / \mathrm{mm}^{3}$. Biochemical parameters were in normal ranges. A hypoechoic solid mass lesion at segments 4-8 of the liver, which was compatible with hemangioma and hydrops of GB, and increased GB wall thickness were the main findings of abdominal ultrasonography. Moreover, cholelithiasis was absent. On computerized tomography, there was no additional finding in the examination of the abdomen (Figure 1). Subsequently, an abdominal exploration decision was made under the guidance of physical examination signs. A median laparotomy was performed after obtaining a written informed consent from the patient. In addition, the appendix was normal. There was serohemorrhagic fluid collection at the pelvis and left lower quadrant. GB was gangrenous and congested (Figure 2 and 3). GB had a loose meso and was torsioned by a rotation of $360^{\circ}$ around itself. Cholecystectomy was performed after the detorsion of GB (Figure 4). There was no additional finding. The patient was discharged on the $6^{\text {th }}$ postoperative day with no complication.

\section{Discussion}

Gallbladder torsion is a rare cause of acute abdomen. Eighty-five percent of the affected patients are between the age of 60 and 80 years. Female/male ratio is $3 / 1(7,8)$. Etiology of $G B$ torsion is not clearly defined, but risk factors have been identified. Usually, GB meso is very long and loose in these patients. Elderly patients and patients with liver atrophy, decreased fat tissue in the abdomen, kyphoscoliosis, atherosclerosis of the cystic artery, and increased peristalsis of neighboring organs were defined as predisposal factors (7-9). GB stones were found in only $20 \%-50 \%$ of these patients, and it has been suggested that they had no importance as an etiological factor (10).

The symptoms of GB torsion are usually nonspecific and mimic those of acute cholecystitis. There may be complete or incomplete torsion. Torsion with a degree of rotation of less than $180^{\circ}$ is defined as incomplete. In this situation, clinical signs may mimic biliary colic. In complete torsion, GB perfusion is deteriorated, and patients show the signs of acute cholecystitis (7-9). Physical examination findings may be nonspecific, but many patients have clinical signs of acute cholecystitis at admission. Laboratory studies are usually nondiagnostic. 


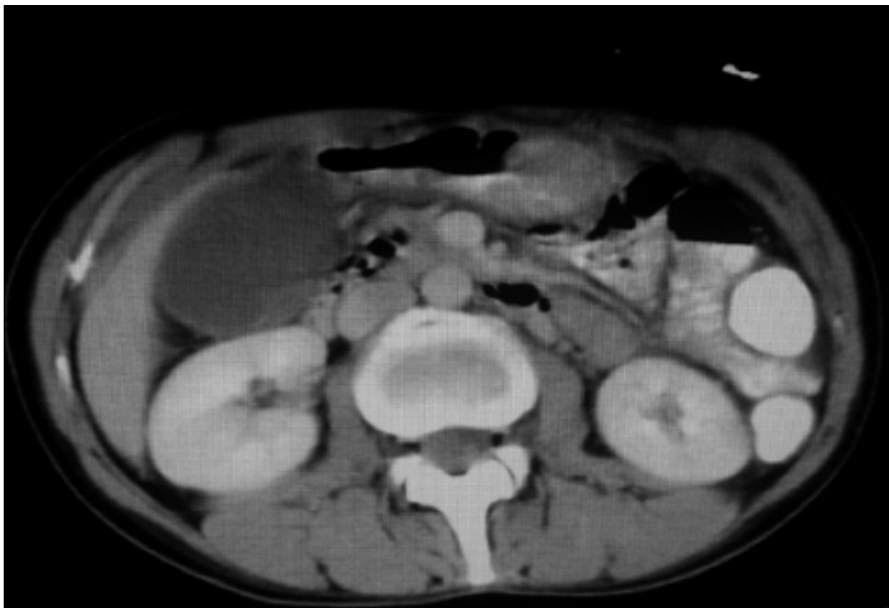

Figure 1. Computerized tomography image of gallbladder torsion

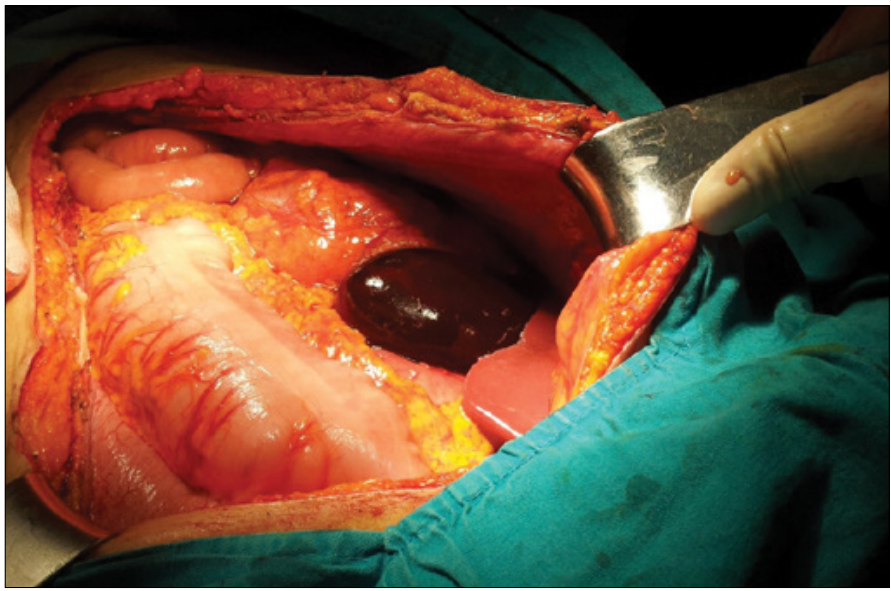

Figure 2. Gallbladder during laparotomy

Despite the recent developments in imaging modalities, it is difficult to diagnose with imaging studies. Usually, diagnosis is performed during operation. However, ultrasonography, computerized tomography, doppler ultrasonography, and magnetic resonance imaging are the commonly used radiological modalities in diagnosis (10-12).

In this case, we performed a laparotomy as there was a lack of preoperative diagnosis. If imaging studies clearly diagnosed GB torsion, laparoscopic cholecystectomy may be performed as the operation of choice.

\section{Conclusion}

Gallbladder torsion is a rare situation that is difficult to diagnose preoperatively and needs urgent surgical management. Suspicion with only clinical findings, urgent diagnosis and management are very important in this fatal disease.

Informed Consent: Written informed consent was obtained from patient who participated in this case.

Peer-review: Externally peer-reviewed.

Conflict of Interest: No conflict of interest was declared by the authors.

Financial Disclosure: The authors declared that this study has received no financial support.

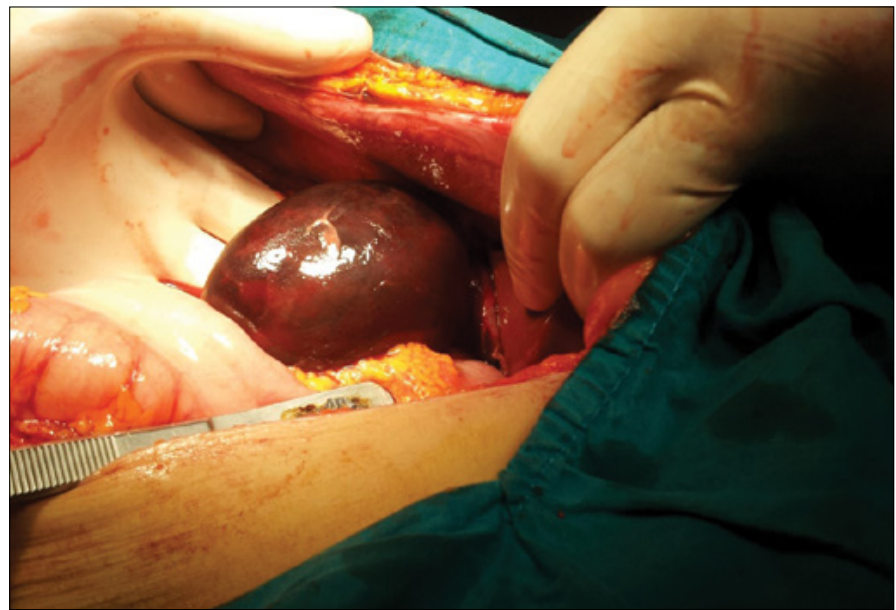

Figure 3. Torsioned gallbladder

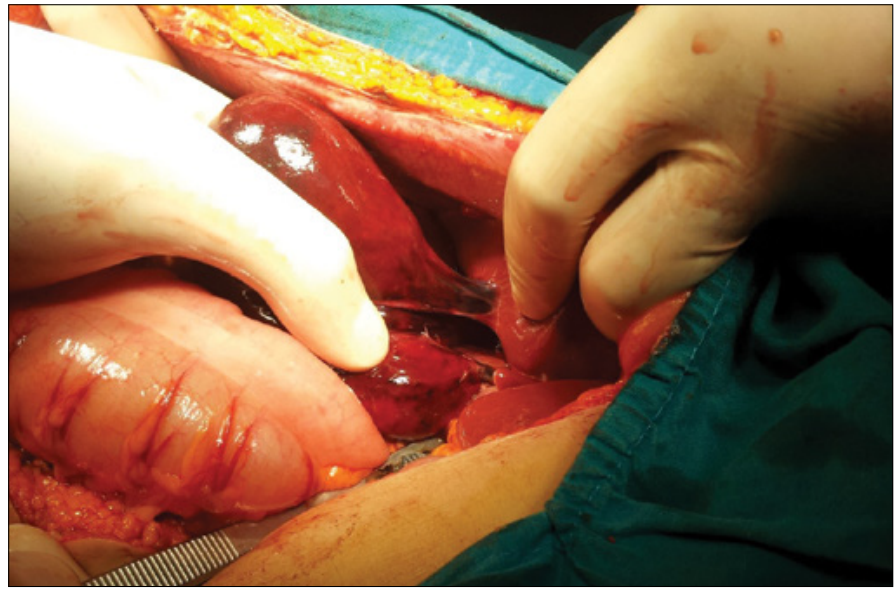

Figure 4. Detorsioned gallbladder

\section{References}

1. Wendel AV. A case of floating gall-bladder and kidney complicated by cholelithiasis, with perforation of the gall-bladder. Ann Surg 1898; 27: 199-202.

2. Nakao A, Matsuda T, Funabiki S, Mori T, Koguchi K, Iwado T, et al. Gallbladder torsion: case report and review of 245 cases reported in the Japanese literature. J Hepatobiliary Pancreat Surg 1999; 6: 418-21. [CrossRef]

3. Ijaz S, Sritharan K, Russell N, Dar M, Bhatti T, Ormiston M. Torsion of the gallbladder: a case report. J Med Case Reports 2008; 2: 237. [CrossRef]

4. Bothra R. Torsion of the gall-bladder in the aged. Br J Surg 1973; 60:359-60. [CrossRef]

5. Losken A, Wilson BW, Sherman R. Torsion of the gallbladder. Am Surg 1997; 63: 975-8.

6. Shaikh AA, Charles A, Domingo S, Schaub G. Gallbladder volvulus: report of two original cases and review of the literature. Am Surg 2005; 71: 87-9.

7. Tarhan OR, Barut I, Dinelek H. Gallbladder volvulus: review of the literature and report of a case. Turk J Gastroenterol 2006; 17: 209-11.

8. Janakan G, Ayantunde AA, Hoque H. Acute gallbladder torsion: an unexpected intraoperative finding. World J Emerg Surg 2008; 3: 9. [CrossRef]

9. Cho YP, Kim HJ, Jung SM, Kang GH, Han MS, Jang HJ. Torsion of the gallbladder: report of a case. Yonsei Med J 2005; 46: 862-5. [CrossRef]

10. Ikematsu Y, Yamanouchi K, Nishiwaki Y, Kida H, Waki S, Okawada T. Gallbladder volvulus: experience of six consecutive cases at an institute. $J$ Hepatobiliary Pancreat Surg 2000; 7: 606-9. [CrossRef]

11. Kitagawa $H$, Nakada K, Enami T, Yamaguchi T, Kawaguchi F, Nakada M. Two cases of torsion of the gallbladder diagnosed preoperatively. J Pediatr Surg 1997; 32: 1567-9. [CrossRef]

12. Merine D, Meziane M, Fishman EK. CT diagnosis of gallbladder torsion. J Comput Assist Tomogr 1987; 11: 712-3. [CrossRef] 